\title{
DRUG PERMEABILITY ACROSS A PHOSPHOLIPID
}

\author{
VESICLE-BASED BARRIER:
}

\section{THE EFFECT OF TENSIDES, CO-SOLVENTS AND pH CHANGES ON BARRIER INTEGRITY AND ON DRUG}

\section{PERMEABILITY}

\author{
Gøril Eide Flaten ${ }^{1}$, Kristina Luthman ${ }^{2}$, Terje Vasskog ${ }^{3}$, Martin Brandl ${ }^{1 *}$ \\ ${ }^{1}$ University of Troms $\varnothing$, Institute of Pharmacy, Department of Pharmaceutics \& \\ Biopharmaceutics, N-9037 Troms $\varnothing$, Norway \\ ${ }^{2}$ University of Gothenburg, Department of Chemistry, Medicinal Chemistry, \\ SE-412 96 Gothenburg, Sweden \\ ${ }^{3}$ University of Troms $\emptyset$, Institute of Pharmacy, Department of Medicinal Chemistry, N-9037 \\ Tromsø, Norway
}

*To whom correspondence should be addressed. Department of Pharmaceutics \& Biopharmaceutics, Institute of Pharmacy, University of Troms $\emptyset$, N-9037 Troms $\varnothing$, Norway. Phone: +47 77646159. Fax: +47 77646151. E-mail: Martin.Brandl@farmasi.uit.no 
Abstract

In this study the integrity of the recently developed phospholipid vesicle-based permeability barrier in the presence of a variety of co-solvents and tensides has been investigated. Also included are studies of the influence of these additives on drug permeation and the effect of $\mathrm{pH}$ changes on the permeability of ionogenic drug compounds.

Permeability experiments using the hydrophilic model compound calcein together with polysorbate 80 (Tween 80), polyoxyl 35 castor oil (Cremophor EL), macrogol lauryl ether (Brij 35), sorbitan monolaurate (Span 20), polyethylene glycol 400 (PEG 400), ethanol and dimethylsulphoxide (DMSO) were performed to determine whether the barriers were affected by the presence of these additives in the donor compartment. It was found that the integrity of the phospholipid vesicle-based barriers did not seem to be influenced by Span 20 up to a concentration of $5 \mathrm{mg} / \mathrm{ml}$, PEG 400 up to a concentration of $40 \mathrm{mg} / \mathrm{ml}$ and ethanol and DMSO up to a concentration of $20 \mathrm{mg} / \mathrm{ml}$, respectively. Brij 35, Tween 80 and Cremophor EL were however found to be incompatible with the model at all concentrations as the barriers became leaky. Appearance of phospholipid in the donor chamber in presence of these three tensides indicated that the loss of integrity was due to partial dissolution of the phospholipid vesicles from the barrier. The permeability of testosterone was not significantly improved by the presence of the different co-solvents, except for $40 \mathrm{mg} / \mathrm{ml}$ PEG 400 and $20 \mathrm{mg} / \mathrm{ml}$ DMSO where the permeability was increased.

In the $\mathrm{pH}$ study the permeability of metoprolol and naproxen was shown to decrease with increasing degree of ionisation according to the $\mathrm{pH}$ partition hypothesis. This renders the permeability model suitable for using $\mathrm{pH}$-shift as a factor to influence solubility of drugs as well as to predict segmental absorption in the gastrointestinal tract. 
Keywords: Artificial membrane, liposomes, phospholipid, pH, bilayer, drug permeability, tensides, surfactants, co-solvents, flux, solubility enhancing agents, phospholipid dissolution

\section{Introduction}

Screening of permeability properties of new drug candidates using different types of permeability models has become an essential part of early drug development. A variety of tensides and co-solvents have lately been commonly used in formulations together with the drug candidates to ensure therapeutic concentrations after oral administration. It is therefore important to secure the integrity of permeability barriers in the presence of tensides and cosolvents of interest.

The phospholipid vesicle-based model used in this study is developed for screening of passive drug permeability. The permeation barriers consist of a tight barrier of liposomes on a filter support, packed by use of centrifugation (Flaten et al., 2006a; Flaten et al., 2006b; Flaten et al., 2007). This is the first successful attempt to deposit lipids without the use of an inert solvent such as hexadecane. The apparent permeability coefficients obtained from the phospholipid vesicle-based model have been shown to correlate well with literature data on human absorption in vivo. The model differs from other permeability models in that agitation to reduce the unstirred water layer is not needed to increase the permeability, not even for highly lipophilic drugs such as testosterone. This is explained by the morphology of the vesicle-based barrier which mainly consists of aqueous compartments immobilised within a matrix of phospholipid vesicles (Flaten et al., 2007). The permeability data obtained without the use of agitation correlate well with the fraction absorbed in humans after oral administration.

When changes in permeability in the presence of tensides and co-solvents are observed it is essential to first investigate if any modifications of the permeation barrier have occurred and 
if the integrity is maintained. Conclusions from the permeability studies cannot be drawn if this is not properly done. In this study we have therefore investigated the integrity of the phospholipid vesicle-based barriers, in the presence of a variety of commonly used tensides and co-solvents. We have also studied how these additives influence on the permeation of the model drug testosterone. The results showed that the model is compatible with relevant tensides and co-solvents, whereof some led to slightly increased permeability of testosterone.

A useful in vitro permeability model should produce permeability values which correlate well with in vivo permeability data. To reach this ambition it is important that the model mimics the in vivo situation as closely as possible. The $\mathrm{pH}$ in the gastrointestinal tract is increasing from the acidic environment in the stomach to the more basic conditions in the last part of the small intestine and the large intestine. In addition, the $\mathrm{pH}$ differs under fasted and fed states. The median $\mathrm{pH}$ in the duodenum has been reported to be 6.1 in the fasted state with a decrease to $\mathrm{pH} 5.4$ when feeding a meal (Dressman et al., 1990). Between the proximal jejunum and the distal ileum the $\mathrm{pH}$ gradually increases from around 6 to about 8 (Avdeef, 2003). The integrity of the phospholipid vesicle-based barriers has earlier shown to be maintained within a pH range from 2.0 to 8.0 (Flaten et al., 2006a) which makes the model suitable for studies on the permeability of poorly soluble protolytic compounds as well as to provide insight into segmental absorption in the human gastrointestinal tract. In this study the permeability of an acidic (naproxen) and a basic (metoprolol) drug compound has been measured at $\mathrm{pH} 5.0,6.2$ and 7.4 to investigate how the $\mathrm{pH}$ changes affect the permeability of ionogenic compounds. The results showed that the permeability of metoprolol and naproxen decreased with increasing ionisation according to the $\mathrm{pH}$ partition hypothesis. 


\section{Experimental section}

\subsection{Materials}

Egg phosphatidylcholine, Lipoid E-80, was obtained from Lipoid, Ludwigshafen, Germany. Testosterone, naproxen, metoprolol tartrate and calcein were purchased from Sigma-Aldrich Co, St. Louis, LA, USA. Polysorbate 80 (Tween 80), polyoxyl 35 castor oil (Cremophor EL), macrogol lauryl ether (Brij 35), sorbitan monolaurate (Span 20), polyethylene glycol 400 (PEG 400), ethanol and dimethylsulphoxide (DMSO) were obtained from Sigma-Aldrich Chemie $\mathrm{GmbH}$, Steinheim, Germany and $\mathrm{D}_{3}$-testosterone was obtained from Toronto Research Chemicals, North York, Canada. Filter inserts (Transwell, $\mathrm{d}=6.5 \mathrm{~mm}$ ) and plates were purchased from Corning Inc, Corning, NY, USA, and the mixed cellulose ester filters (0.65 $\mu \mathrm{m}$ pore size) were obtained from Millipore, Billerica, MA, USA.

\subsection{Methods}

\subsubsection{Preparation of the barrier}

The phospholipid vesicle-based barriers were prepared according to the procedure earlier described (Flaten et al., 2006b) and were stored for up to two weeks at $-80{ }^{\circ} \mathrm{C}$ in accordance with previous stability studies (Flaten et al., 2006a). In brief, liposome dispersions extruded through filters with pore size $800 \mathrm{~nm}$ and $800+400 \mathrm{~nm}$, respectively, were deposited on a filter support by use of centrifugation. The liposomes were added in consecutive steps, first the smaller liposomes and then the larger ones. Freeze-thaw cycling was then used to promote fusion of the liposomes and hence produce a tight barrier. 
2.2.2 Quantification of testosterone by high performance liquid chromatography mass spectrometry (HPLC-MS/MS)

Testosterone was quantified on a 2695 separation unit from Waters, Milford, MA, USA coupled to a Quattro LC mass spectrometer from Micromass, Manchester, UK. The analysis was performed on a Gemini $\mathrm{C}_{18}$ column $(2.0$ x $50 \mathrm{~mm}, 5 \mu \mathrm{m}$ hybrid particles, $110 \AA$ pore size, $375 \mathrm{~m}^{2} / \mathrm{g}$ surface area, $14 \%$ carbon load) from Phenomenex, Torrance, CA, USA, with a mobile phase consisting of high performance liquid chromatography (HPLC) grade acetonitrile from Merck, Darmstadt, Germany, purified water obtained from a MilliQ purification unit from Millipore, and pro analysis grade formic acid from Merck. The following gradient was selected for separation: solvent A consisting of purified water with 0.1 $\%$ formic acid, and solvent B consisting of $90 \%$ HPLC grade acetonitrile from Merck, $10 \%$ purified water, and $0.1 \%$ formic acid. The gradient started with a 1 min isocratic elution with $40 \% \mathrm{~B}$, followed by a 1-6 min linear increase to $54 \% \mathrm{~B}$. The total runtime was $6 \mathrm{~min}$. The flow rate was $0.2 \mathrm{~mL} / \mathrm{min}$, and the injection volume was $5 \mu$. The sample temperature in the autosampler was set to $8{ }^{\circ} \mathrm{C}$ and the draw speed to "slow". Blank injections of water or $\mathrm{MeOH}$ were performed regularly to ensure that there were no carry-over effects.

Quantification was performed on a triple quadrupole mass spectrometer in multiple reaction monitoring mode (MRM). The compounds were ionized by applying positive electrospray ionization $\left(\mathrm{ESI}^{+}\right)$and the ions introduced to the mass filters through a Z-spray source. The collision cell gas pressure was kept at $1.5 \times 10^{-3} \mathrm{~Pa}$, and argon 4.0 (Hydro Gas and Chemicals AS, Oslo, Norway) was used as collision gas. The following optimized parameters were used for both compounds: Capillary voltage $3.30 \mathrm{kV}$, extractor voltage $4 \mathrm{~V}$, RF lens $0.4 \mathrm{~V}$, source temperature $100{ }^{\circ} \mathrm{C}$, desolvation temperature $250{ }^{\circ} \mathrm{C}$, low mass resolution 1 and high mass resolution 1 were 15.0, low mass resolution 2 and high mass resolution 2 were 14.0. The nebuliser gas was set to $25 \mathrm{l} / \mathrm{h}$, and the desolvation gas to $1000 \mathrm{l} / \mathrm{h}$ (both nitrogen 4.0 , Hydro 
Gas and Chemicals AS). The ion energy 1 and 2 were set to 1.0, and the entrance and exit values to zero. The pseudo-molecular ion $[\mathrm{M}+\mathrm{H}]^{+}$was used as precursor ion for both compounds, and the ion transitions used for quantification were $292 \rightarrow 109$ for $\mathrm{D}_{3}$ testosterone, and $289 \rightarrow 97$ for testosterone. For both compounds the cone voltage was set to $35 \mathrm{~V}$, the collision energy to $20 \mathrm{eV}$, the dwell time to $0.5 \mathrm{~s}$, the inter-channel delay to $0.1 \mathrm{~s}$, and the span to $0.1 \mathrm{Da}$. The ratio between the area of the testosterone and the external standard $\mathrm{D}_{3}$-testosterone peaks was used for quantification.

\subsubsection{Use of tensides and co-solvents in the phospholipid vesicle-based model}

2.2.3.1 Stability of the barriers in presence of tensides and co-solvents in terms of electrical resistance and permeability of calcein

It has earlier been found that calcein can be used to monitor the tightness of the barrier and calcein permeation studies were thus performed as earlier described (Flaten et al., 2006b). The inserts were loaded with calcein solutions $(11 \mathrm{mM})$ containing different concentrations of additives (Table 1). All the surfactants were used in concentrations above their critical micelle concentrations $(\mathrm{cmcs})$. The experiments were done in triplicate with six inserts in each parallel, except for Tween 80 and Brij 35 where only one parallel, each with six inserts, was performed. The electrical resistances across the barriers were also measured at the end of the experiments.

Table 1 
2.2.3.2 Stability of the phospholipid vesicle-based barriers in presence of tensides and cosolvents in terms of release of phospholipid

Permeability experiments were run by loading inserts containing the liposome barriers with solutions of the different solubility enhancing agents and placing them in acceptor chambers containing phosphate buffer ( $\mathrm{pH}$ 7.4) as described earlier (Flaten, et al., 2006b). The only exception was that the inserts were not moved to fresh wells at certain time intervals but left in the same acceptor well for $5 \mathrm{~h}$. Samples were withdrawn from both donor and acceptor chambers and dissolved in sodium cholate solution $(0.83 \mathrm{mg} / \mathrm{ml})$. The amount of egg phosphatidylcholine was quantified as described earlier (Flaten et al., 2006a; Flaten et al., 2006b; Grohganz et al., 2003) with the following adaptations: $50 \mu 1$ of the samples and $250 \mu 1$ of the phospholipid B-enzymatic colorimetric reagent were mixed in a 96-well titer plate and incubated for $45 \mathrm{~min}$ in the titer plate reader at $37{ }^{\circ} \mathrm{C}$, with shaking for the first $5 \mathrm{~min}$. The UV-absorption at $492 \mathrm{~nm}$ was measured and evaluated against standard solutions of egg phosphatidylcholine and cholate. The results are reported as the mean amount of egg phosphatidylcholine of six inserts.

\subsubsection{Investigation of the effects of co-solvents on the flux of testosterone}

Saturated solutions of testosterone containing different concentrations of co-solvents (ethanol, DMSO and PEG 400) were prepared by adding excess testosterone to solutions of the additives. The solutions were allowed to stand at room temperature for 2 days with repetitive intervals of sonication and the excess testosterone was finally filtered off from the solutions using $0.22 \mu \mathrm{m}$ syringe filters. The concentration of testosterone in solution was then quantified using high performance liquid chromatography mass spectrometry as described in section 2.2.2. $\mathrm{D}_{3}$-testosterone was added as an external standard to a final concentration of 0.3 $\mathrm{ng} / \mathrm{ml}$ in each sample. Permeation experiments with the freshly prepared saturated solutions of 
testosterone in ethanol, DMSO and PEG 400, respectively, were performed to determine whether the addition of the co-solvents would affect the flux of the drug. The permeation experiments were performed as described earlier (Flaten et al., 2006b) with the exception that the amount of testosterone in the acceptor and donor chambers were quantified using HPLCMS/MS as explained in section 2.2.2. $\mathrm{D}_{3}$-testosterone was added as an external standard to a final concentration of $0.3 \mathrm{ng} / \mathrm{ml}$ in each sample. The concentrations of co-solvents used were 10, 20 and $40 \mathrm{mg} / \mathrm{ml}$ (Figure 4). The experiments were done in triplicate with six inserts in each parallel. The reason for choosing a different analytical technique compared to what is described earlier is that testosterone shows a low UV absorbance. By using HPLC-MS/MS the quantification was more sensitive, without interference from the co-solvents.

\subsubsection{Influence of $\mathrm{pH}$ on the permeability of acidic and basic drugs}

The effect of $\mathrm{pH}$ changes on the permeability of drugs was investigated by determining the permeability of one acidic and one basic drug compound, naproxen and metoprolol, respectively, at $\mathrm{pH}$ 5.0, 6.2 and 7.4. The permeation experiments were performed as described earlier (Flaten et al., 2006b) with the exception that the $\mathrm{pH}$ in the donor compartment was adjusted to 5.0, 6.2 or 7.4. The buffer used for the donor solution in the experiments at $\mathrm{pH} 5.0$ was isotonic acetate buffer $\mathrm{pH} 5.0^{*}$ and at $\mathrm{pH} 6.2$ and 7.4 isotonic phosphate buffers at the respective $\mathrm{pHs}$ were used. The acceptor solution was always phosphate buffer with $\mathrm{pH} 7.4$ since this phase represents the blood circulation in an in vivo situation.

\footnotetext{
${ }^{*} 0.075 \mathrm{M}$ acetate buffer with $0.15 \mathrm{M}$ sodium chloride
} 


\subsubsection{Statistical methods}

To test if the changes brought about by co-solvents and tensides were significant, student's ttests for comparison of two means was performed. A significance level of $\mathrm{p}=0.05$ was always used. The hypotheses determined the choice of a one or two sided t-test.

\section{Results and discussions}

3.1 Use of tensides and co-solvents in the phospholipid vesicle-based model

In this study it was investigated whether the phospholipid vesicle-based model is suitable for permeability testing in presence of co-solvents and tensides. This was achieved by determining the integrity of the barriers using a variety of additives as well as by investigating how these additives influence the permeation of drugs.

3.1.1 Stability of the barriers in presence of tensides and co-solvents in terms of electrical resistance and permeability of calcein

Investigation of the integrity of the barriers was performed by measuring the permeability of the hydrophilic marker calcein in the presence of different tensides and co-solvents, as well as by measuring electrical resistance across the barriers after ended experiments. The calcein permeability in the various experiments using three co-solvents and four tensides are shown in Figure 1 and in Table 2. The electrical resistances across the barriers measured at the end of the experiments are given in Figure 2.

Figure 1

Figure 2 
Electrical resistance or TEER is a parameter that is often used to control the integrity of a permeation barrier in presence of various tensides and co-solvents (Takahashi et al., 2002). Earlier studies have shown that the phospholipid vesicle-based barriers have their integrity intact when the electrical resistance is above $1000 \Omega$. An electrical resistance between 3000 and $1000 \Omega$ is what normally has been observed when using the model (Flaten et al., 2006b). As expected the electrical resistance measured across the barriers after ended experiments were found to decrease with increasing permeability of calcein. When the calcein permeability was drastically increased the resistance decreased from about $2000 \Omega$ to around $500 \Omega$. Figure 3 illustrates the decrease in electrical resistance with increasing permeability of calcein in the presence of increasing concentrations of Span 20.

Figure 3

The results in Figures 1 and 2 show that the presence of Brij 35, Tween 80 and Cremophor EL in the donor chamber appeared to induce large increases in the permeability of calcein and a simultaneous decrease in the electrical resistance below $1000 \Omega$ even at low concentrations. For ethanol, DMSO and PEG 400 no significant increase in permeability of calcein or change in electrical resistance was observed up to a concentration of $40 \mathrm{mg} / \mathrm{ml}$. However, at 40 $\mathrm{mg} / \mathrm{ml}$ ethanol the standard deviation of the permeability value increased. Span 20 resulted in a significant change in permeability of calcein at concentrations $\geq 7.5 \mathrm{mg} / \mathrm{ml}$, but below this limit its presence did not lead to significant changes neither in permeability nor electrical resistance (Figure 3).

Table 2 
The results thus show that the phospholipid vesicle-based model seems to be compatible with ethanol and DMSO up to a concentration of $20 \mathrm{mg} / \mathrm{ml}$. Above this concentration the reproducibility decreased, and therefore this was set as the limit for the subsequent studies using drugs. The barriers were compatible with Span 20 at concentrations up to $5 \mathrm{mg} / \mathrm{ml}$ while PEG 400 appears as a proper co-solvent for our model in the whole concentration range tested and was thus used up to $40 \mathrm{mg} / \mathrm{ml}$ in subsequent permeability tests with drugs. In contrast, Brij 35, Tween 80 and Cremophor EL seemed to disrupt the structure of the barrier to a large extent even at low concentrations, which renders them unsuitable as additives in this model.

For the most often used permeability assays, PAMPA and the Caco-2-cell model, a variety of solubility enhancing agents have been tested. Acetonitrile has been a common co-solvent in the PAMPA models (Kansy et al., 1998) which are also compatible with a variety of tensides (Bendels et al., 2006; Liu et al., 2003). For the Caco-2 model some solubility enhancing agents and even mixtures of these have shown not to effect the viability of 21-day cultured Caco-2 monolayers (Takahashi et al., 2002).

However, intact intestinal membranes are often found to be more resistant to cytotoxic effects of tensides and co-solvents than is the case for cell culture models and artificial models like the phospholipid vesicle-based assay. The intestinal membrane is covered with a mucus layer that protects the underlying membrane against elements in the luminal fluid and has also a mechanism for recovery from any trauma. A disruption of the permeation barrier used in this study in the presence of some tensides does thus not necessary mean that this would be the case for the intestinal membrane in vivo. In cases where permeability enhancers have been reported to have a direct effect on the membrane this is often connected to the tight junctions and not to a disruption of the cell bilayer (Aungst, 2000). 
3.1.2 Stability of the barriers in presence of tensides and co-solvents in terms of release of phospholipid

To clarify the mechanism behind the loss of the barrier integrity in the presence of some of the additives, the appearance of phospholipid in the acceptor and donor compartments during the incubation was investigated.

The amount of egg phosphatidylcholine in the donor and acceptor phases after $5 \mathrm{~h}$ of incubation was quantified by using a phospholipid B-enzymatic colorimetric test kit. The amount of phospholipid found in the donor compartments differed in the presence of the various tensides and co-solvents, whereas no phospholipid could be detected in the acceptor phases. The results are shown in Figure 4.

Figure 4

All additives that resulted in increased calcein permeability except Span 20 (Brij 35, Tween 80 and Cremophor EL) seem to partly dissolve the barrier, leading to a release of phospholipid into the donor phase. Span 20 does not seem to dissolve the phospholipid vesicles in the barrier, even though an increased permeability of calcein was observed at the highest concentrations. The mechanism behind the loss of barrier integrity in the presence of high concentrations of Span 20 must therefore be different from that revealed for the other surfactants tested. One possible explanation can be that Span 20 makes transient pores in the bilayers, and thereby increases the permeability of calcein across the barrier. Another tenside, cholate, has been reported to show this behaviour at low concentrations (Schubert et al., 1986).

3.1.3 Use of co-solvents to influence the flux of lipophilic drugs

To investigate the influence of co-solvents on the permeability of drug compounds, permeability experiments with solutions of testosterone and those co-solvents shown to not 
affect the integrity of the barriers, were performed. Testosterone was chosen because it is a rather lipophilic drug with poor water solubility for which co-solvents can be beneficial for permeability.

The results show that the permeability of testosterone was not significantly increased in the presence of ethanol or the lowest concentration of DMSO or PEG 400, compared to control experiments (Figure 5). There was neither any significant change in mass balance in any of the experiments (data not shown). Only by increasing the concentration of PEG 400 and DMSO a slight but significant increase in permeability of testosterone could be observed. For the flux values for testosterone (Figure 6) the same trend was observed. The reason for reporting both the permeability and flux values is to facilitate comparisons with other reports in the literature.

Figure 5

Figure 6

When surfactants or complexing agents are used, permeability estimations may be altered due to a reduction in thermodynamic activity. Underestimation of the true permeability could occur since drug that is free in solution may be more readily available for diffusion across the membrane than complexed or micellary bound drug (Katneni et al., 2006), whether this holds true also for co-solvents remains unclear. The permeability of carbamazepine across rabbit intestine has been reported in the literature to decrease with increasing concentrations of PEG 400. The decreased permeability was explained by a reduction in the thermodynamic activity of the drug with increasing concentrations of PEG 400 (Riad and Sawchuk, 1991). Bendels and co-workers reported enhanced permeability across a PAMPA barrier of weak acids and neutral compounds whereas permeability of weak bases was depressed in presence of e.g. 
PEG 400 (Bendels et al., 2006). However, they did not investigate the integrity of the permeation barrier under the influence of the chosen additives before the permeability experiment and the reason for the observed changes is therefore difficult to define. Unchanged permeability values for poorly water-soluble drugs in the presence of e.g. PEG 400 has also been reported in the Caco-2 model (Takahashi et al., 2002). This is in contrast to another report (Yamashita et al, 2000) where the permeability of dexamethason was found to be unchanged in the presence of ethanol but decreased in the presence of both PEG 400 and DMSO (Yamashita et al., 2000). A decrease in electrical resistance was however observed with all these additives which could change the permeability of dexamethason. Saha and Kou also reported an increased flux of poorly water soluble compounds after addition of e.g. PEG 300 and a decreased flux when using e.g. a mixture of propylenglycol and Tween 80 (Saha and Kou, 2000). But also here there was a significant change in electrical resistance in some of the experiments.

The inconsistent information found in the literature, as well as the lack of control of or changes in the integrity of the barrier, makes it difficult to delineate the effects of co-solvents on flux/permeability of lipophilic drug compounds. The presence of these additives could affect permeability models in different ways. However, variations in results can also be observed using the same model, especially if the integrity of the permeation barrier is not taken into account when interpreting the results (Takahashi et al., 2002; Yamashita et al., 2000).

The results from the present experiments showed that DMSO or PEG 400 in the highest concentration slightly but significantly increased the permeability of testosterone. DMSO increased the permeability to a higher extent than PEG 400. DMSO is known to enhance the permeability through skin most probably by inducing a gel-to-liquid phase transition in the ceramide bilayer (Notman et al., 2007). 
In the different permeability experiments with testosterone the concentrations in the donor compartment $\left(\mathrm{C}_{\mathrm{D}}\right)$ were practically the same, the reason for the increased flux/permeability must thus be due to an influence on the barrier diffusion (D) and/or the distribution coefficient (K) according to equation 1 . The thickness of the permeation barrier is given by $\mathrm{h}$ in the equation

$$
J=\frac{d M}{d t} \cdot \frac{1}{A}=\frac{D \cdot K \cdot C_{D}}{h}
$$

To investigate the effect of addition of co-solvent both in the donor and acceptor compartment, permeability experiments using $40 \mathrm{mg} / \mathrm{ml}$ PEG 400 in both compartments were performed. PEG 400 was chosen as it gave an increased permeability of testosterone in our initial experiments. However, addition of PEG 400 to both compartments did not have any significant influence on the flux of testosterone beyond the effect seen with PEG 400 only in the donor chamber (data not shown). One explanation could be that PEG is permeating across the barrier and by that reducing the difference in concentration gradients between the two experiments. On the other hand, an equilibration of PEG between the donor and acceptor phase during the experiment time is unlikely to occur $(30-60 \mathrm{~min})$. The solubility of testosterone in the presence of PEG 400, and hence the concentration in the donor chamber, thus seems to be the rate limiting factor, and the permeation across the boundary surface between the hydrophilic donor solution and the lipophilic barrier appears to be the rate limiting step, in the permeation process of testosterone. This thus shows that the barrier can change character to some degree without resulting in changes in integrity.

However, since we had performed a thorough study of how the tensides and co-solvents affected the barrier the optimal additives could be selected before performing studies of the 
permeability of testosterone. Thus, the observed changes in the permeability values are due to real changes in permeability of the drug and not to changes in the barrier integrity.

\subsection{Use of $\mathrm{pH}$ changes to influence the permeability of acidic and basic drugs}

Earlier studies (Flaten et al., 2006a) have revealed that the integrity of the phospholipidvesicle based barriers is maintained within a $\mathrm{pH}$ range from 2.0 to 8.0 . This makes the model suitable for investigations on how $\mathrm{pH}$ changes can affect the permeability of ionogenic drugs. Therefore, the permeability of one acidic and one basic drug compound, naproxen and metoprolol, respectively, was investigated at three different $\mathrm{pH}$ values $(\mathrm{pH} 5.0,6.2$ and 7.4). The $\mathrm{pH}$ in the acceptor compartment was kept constant at 7.4 since this represent the blood stream in vivo. The permeability values at the different $\mathrm{pH}$ conditions are given in Figure 7.

\section{Figure 7}

As can be seen from Figure 7 the permeability of metoprolol increases with increasing $\mathrm{pH}$, for naproxen the opposite effect was observed. For naproxen the decrease in permeability was significant both from $\mathrm{pH} 5.0$ to 6.2 and from $\mathrm{pH} 6.2$ to 7.4. For metoprolol only the increase in permeability from $\mathrm{pH} 6.2$ to 7.4 was significant. The lack of any significant change in permeability when increasing the $\mathrm{pH}$ from 5.0 to 6.2 is most probably due to the low level of uncharged species at both these $\mathrm{pH}$ values, since metoprolol has a $\mathrm{pK}_{\mathrm{a}}$ value of 9.6. As metoprolol is a basic drug and naproxen an acidic drug this means that the permeability is decreasing with increasing degree of ionisation.

The pH partition theory (Shore et al., 1957) states that it is the uncharged form of ionogenic drug molecules that diffuses across a phospholipid bilayer. Several studies on Caco-2 cells 
have reported increased permeability of basic drug compounds with increasing $\mathrm{pH}$ from 5.0 to 8.0 on the apical side (Neuhoff et al., 2003; Palm et al., 1999), and this also comply with the results from our model. Increased permeability with decreased fraction of ionized drug is in agreement with the $\mathrm{pH}$ partition hypothesis. However, studies in the last decade have shown that also the ionized form significantly partitions into liposome systems and permeate across cell monolayers (Avdeef et al., 1998; Palm et al., 1999; Thomae et al., 2005).

The $\mathrm{pH}$-dependent changes in drug permeability observed in this study are consequences of changes in the fraction of drug in the unionised form $\left(f_{u}\right)$ and not of $\mathrm{pH}$-dependent changes in the phospholipid vesicle-based barrier. Therefore it is possible to use $\mathrm{pH}$ as a factor to increase the solubility and permeability of ionogenic drugs in this model, which also renders the model suitable for studies of segmental absorption in the gastrointestinal tract. Such information is useful e.g. in the development of sustained release formulations of drugs since the drug in this case is released throughout the entire length of the intestine.

\section{Conclusions}

In this study the integrity of the phospholipid vesicle-based barriers in the presence of a set of commonly used surfactants and co-solvents has been investigated. Permeation studies with testosterone together with selected co-solvents were also performed to determine their influence on the flux of a lipophilic drug. In addition the effect of $\mathrm{pH}$ changes on the permeability of ionogenic drug compounds has been studied.

The phospholipid vesicle-based barriers maintained their integrity with respect to permeability of calcein and electrical resistance in the presence of a variety of tensides and co-solvents whereas the permeability of testosterone in the presence of common co-solvents was unchanged, except for $40 \mathrm{mg} / \mathrm{ml}$ PEG 400 and $20 \mathrm{mg} / \mathrm{ml}$ DMSO where a slight but 
significant increased was seen. This is a promising start for further development of the model into a suitable approach for testing of drug permeability in the presence of tensides and cosolvents.

The permeability of the ionogenic drug compounds metoprolol and naproxen decreased with increasing ionisation according to the $\mathrm{pH}$ partition hypothesis. Thus, in this model $\mathrm{pH}$ adjustments can be used to improve solubility of drugs as well as to get information about segmental absorption in the gastrointestinal tract.

\section{Acknowledgments}

The authors thank the Norwegian Research Council (Strategic University Program "Drug Transport and Drug Delivery" as well as a PhD-grant for Gøril Eide Flaten), The Swedish Research Council (grant \#621-2004-4517) and The Knut and Alice Wallenberg Foundation (grant \#98.176) for financial support. We also thank Professor Annette Bauer-Brandl for fruitful discussions on the effect of co-solvents on the behaviour of testosterone in the phospholipid vesicle-based model.

\section{References}

Aungst, B.J., 2000. Intestinal permeation enhancers, J Pharm Sci 89, 429-442

Avdeef, A., 2003, Absorption and Drug Development; Solubility, Permeability and Charge State, Wiley-Interscience, New Jersey p. 116-246.

Avdeef, A., Box, K.J., Comer, J.E.A., Hibbert, C. and Tam, K.Y., 1998. pH-metric logP 10. Determination of liposomal membrane-water partition coefficients of ionizable drugs, Pharm Res 15, 209-215

Bendels, S., Tsinman, O., Wagner, B., Lipp, D., Parrilla, I., Kansy, M. and Avdeef, A., 2006. PAMPA-Excipient Classification Gradient Map, Pharm Res 23, 2525-2535

Dressman, J.B., Berardi, R.R., Dermentzoglou, L.C., Russell, T.L., Schmaltz, S.P., Barnett, J.L. and Jarvenpaa, K.M., 1990. Upper Gastrointestinal (Gi) Ph in Young, HealthyMen and Women, Pharm Res 7, 756-761

Flaten, G.E., Bunjes, H., Luthman, K. and Brandl, M., 2006a. Drug permeability across a phospholipid vesicle based barrier: 2. Characterization of barrier structure, storage stability and stability towards pH changes, Eur J Pharm Sci 28, 336-343 
Flaten, G.E., Dhanikula, A.B., Luthman, K. and Brandl, M., 2006b. Drug permeability across a phospholipid vesicle based barrier: A novel approach for studying passive diffusion, Eur J Pharm Sci 27, 80-90

Flaten, G.E., Skar, M.L., Luthman, K. and Brandl, M., 2007. Drug permeability across a phospholipid vesicle-based barrier: 3. Characterization of drug-membrane interactions and the effect of agitation on the barrier integrity and on the permeability, Eur J Pharm Sci 30, 324-332

Grohganz, H., Ziroli, V., Massing, U. and Brandl, M., 2003. Quantification of various phosphatidylcholines in liposomes by enzymatic assay, AAPS PharmSciTech 4, E63

Kansy, M., Senner, F. and Gubernator, K., 1998. Physicochemical high throughput screening: Parallel artificial membrane permeation assay in the description of passive absorption processes, J Med Chem 41, 1007-1010

Katneni, K., Charman, S.A. and Porter, C.J.H., 2006. Permeability assessment of poorly water-soluble compounds under solubilizing conditions: the reciprocal permeability approach, J Pharm Sci 95, 2170-2185

Liu, H.L., Sabus, C., Carter, G.T., Du, C., Avdeef, A. and Tischler, M., 2003. In vitro permeability of poorly aqueous soluble compounds using different solubilizers in the PAMPA assay with liquid chromatography/mass spectrometry detection, Pharm Res 20, 1820-1826

Neuhoff, S., Ungell, A., Zamora, I. and Artursson, P., 2003. pH-dependent bidirectional transport of weakly basic drugs across Caco-2 monolayers: Implications for drug-drug interactions, Pharm Res 20, 1141-1148

Notman, R., den Otter, W.K., Noro, M.G., Briels, W.J. and Anwar, J., 2007. The permeability enhancing mechanism of DMSO in ceramide Bilayers simulated by molecular dynamics, Biophys J 93, 2056-2068

Palm, K., Luthman, K., Ros, J., Grasjo, J. and Artursson, P., 1999. Effect of molecular charge on intestinal epithelial drug transport: $\mathrm{pH}$-dependent transport of cationic drugs, $\mathrm{J}$ Pharmacol Exp Ther 291, 435-443

Riad, L.E. and Sawchuk, R.J., 1991. Effect of Polyethylene Glycol-400 on the Intestinal Permeability of Carbamazepine in the Rabbit, Pharm Res 8, 491-497

Saha, P. and Kou, J.H., 2000. Effect of solubilizing excipients on permeation of poorly watersoluble compounds across Caco-2 cell monolayers, Eur J Pharm Biopharm 50, 403411

Schubert, R., Beyer, K., Wolburg, H. and Schmidt, K.H., 1986. Structural-Changes in Membranes of Large Unilamellar Vesicles after Binding of Sodium Cholate, Biochemistry 25, 5263-5269

Shore, P.A., Brodie, B.B. and Hogben, C.A.M., 1957. The gastric secretion of drugs: a pH partition hypothesis, J Pharmacol Exp Ther 119, 361-369

Takahashi, Y., Kondo, H., Yasuda, T., Watanabe, T., Kobavashi, S.I. and Yokohama, S., 2002. Common solubilizers to estimate the Caco-2 transport of poorly water-soluble drugs, Int J Pharm 246, 85-94

Thomae, A.V., Wunderli-Allenspach, H. and Kramer, S.D., 2005. Permeation of aromatic carboxylic acids across lipid bilayers: The $\mathrm{pH}$-partition hypothesis revisited, Biophys $\mathbf{J}$ 89, 1802-1811

Yamashita, S., Furubayashi, T., Kataoka, M., Sakane, T., Sezaki, H. and Tokuda, H., 2000. Optimized conditions for prediction of intestinal drug permeability using Caco-2 cells, Eur J Pharm Sci 10, 195-204 


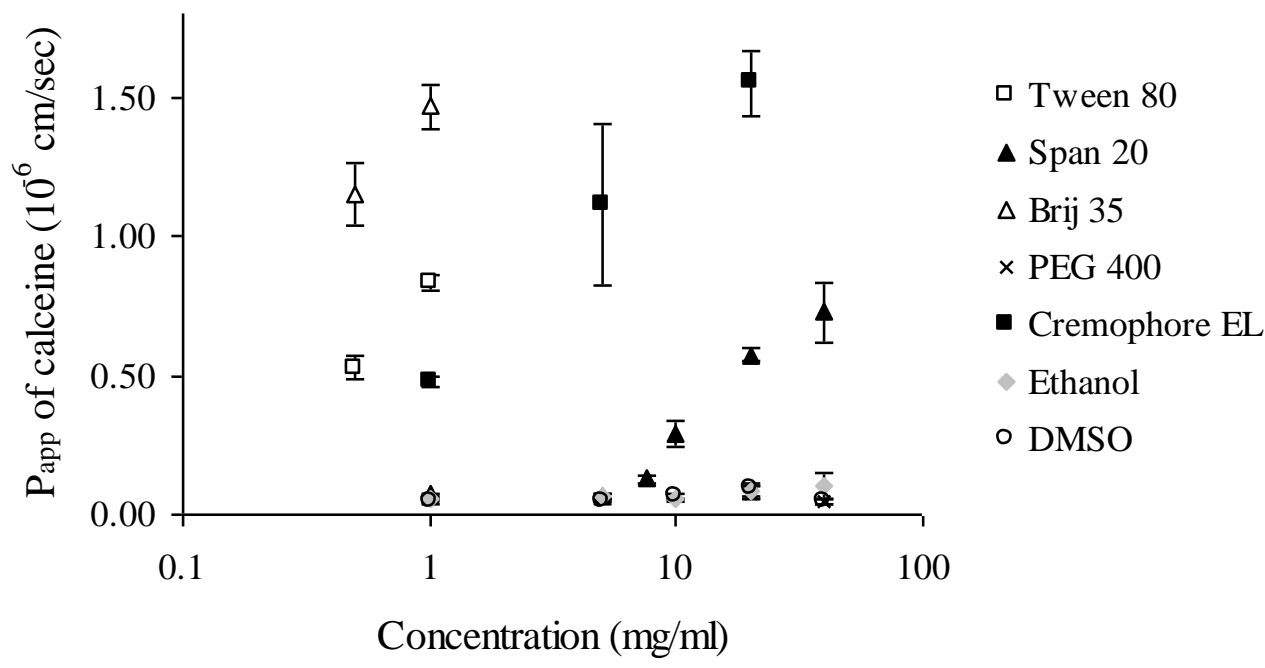

Figure 1: Permeability $\left(\mathrm{P}_{\mathrm{app}}\right)$ values for calcein in the presence of various tensides and cosolvents. The results are shown on a log scale for a better visualization.

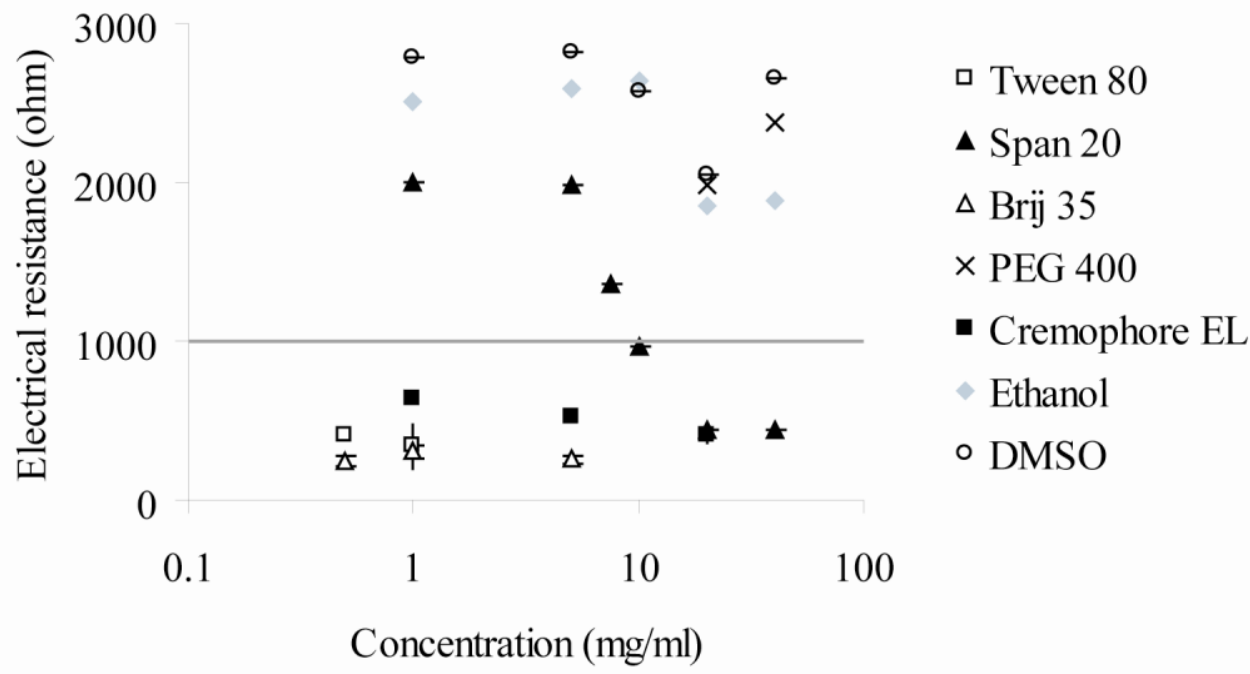

Figure 2: Electrical resistance across the barriers in the presence of various tensides and cosolvents. The results are shown on a log scale for a better visualization and the gray line represents the limit for loss of integrity. 


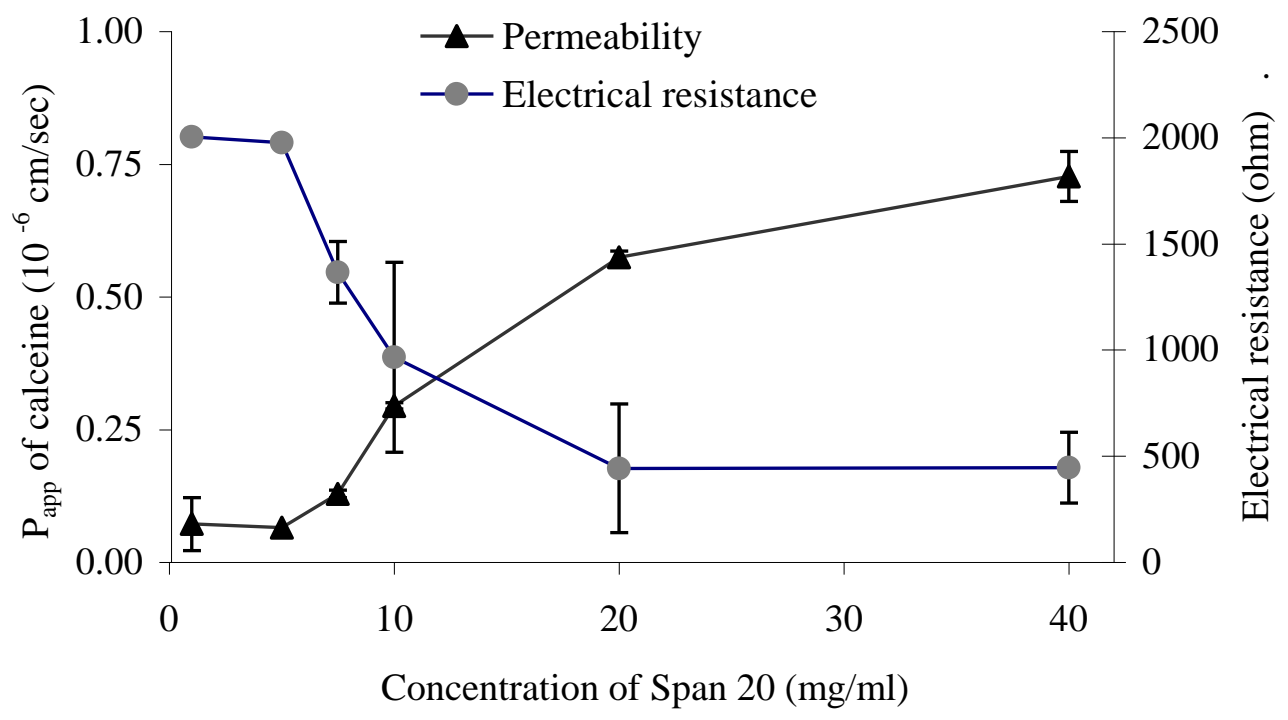

Figure 3

Figure 3: Electrical resistance and permeability $\left(\mathrm{P}_{\mathrm{app}}\right)$ values for calcein in the presence of increasing concentrations of Span 20.

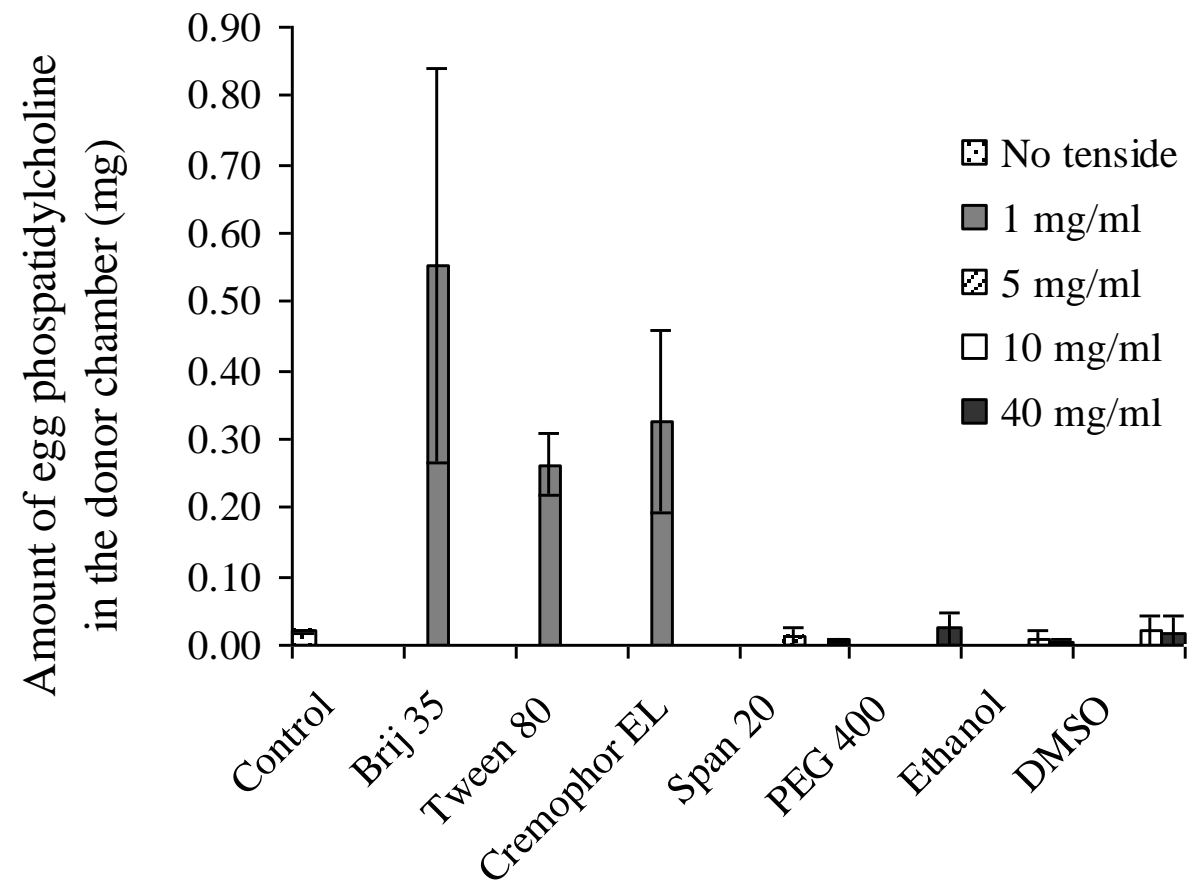

Figure 4

Figure 4: Amount of egg phosphatidylcholine detected in the donor chamber after $5 \mathrm{~h}$ incubation with different tensides and co-solvents. 


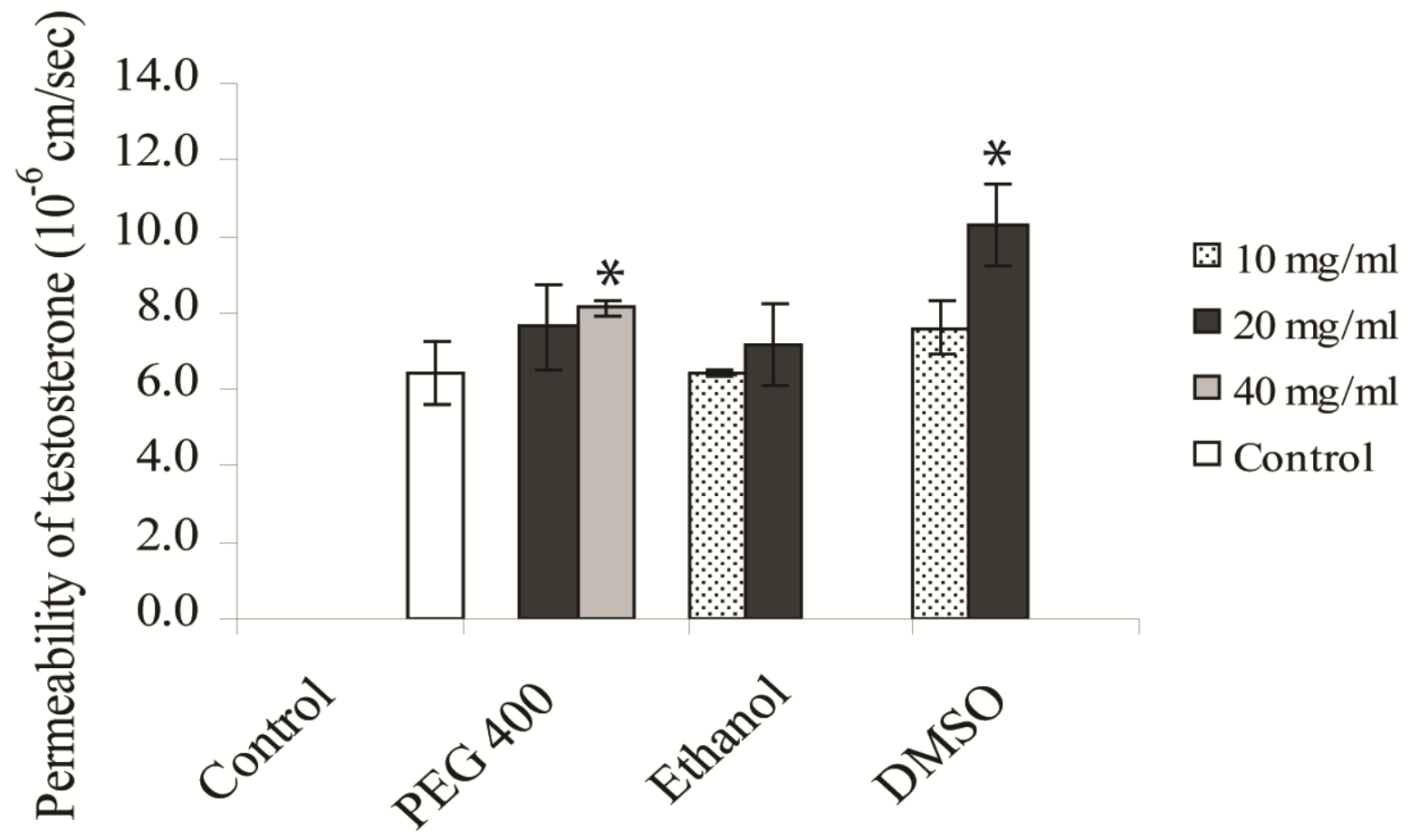

Figure 5: Permeability of testosterone in the presence of different co-solvents. The permeability values that were significantly $(\mathrm{p}=0.05)$ changed as compared to the control value are marked with an asterisk. 


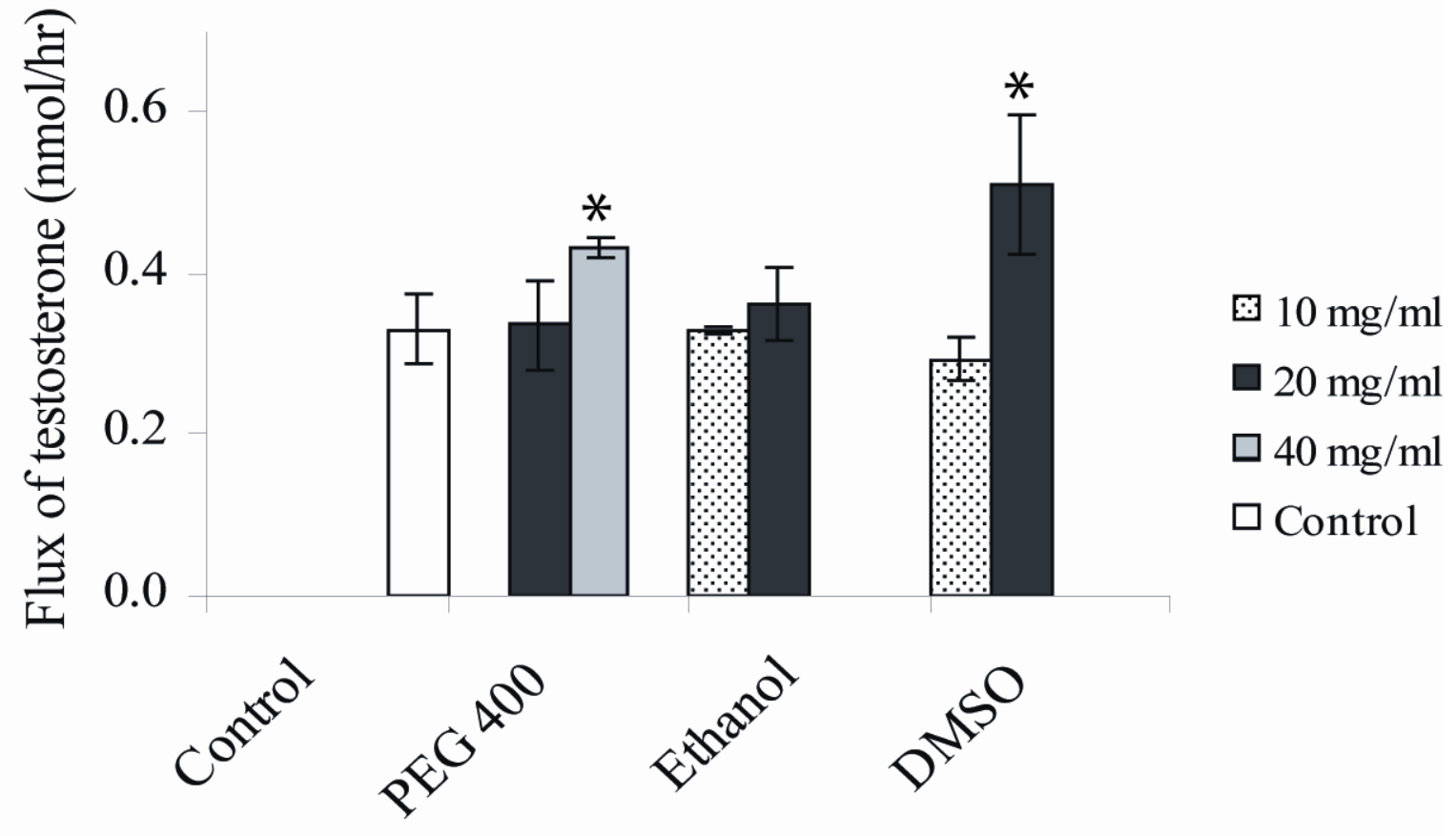

Figure 6: Flux of testosterone in the presence of different co-solvents. The permeability values that were significantly $(\mathrm{p}=0.05)$ changed as compared to the control value are marked with an asterisk. 


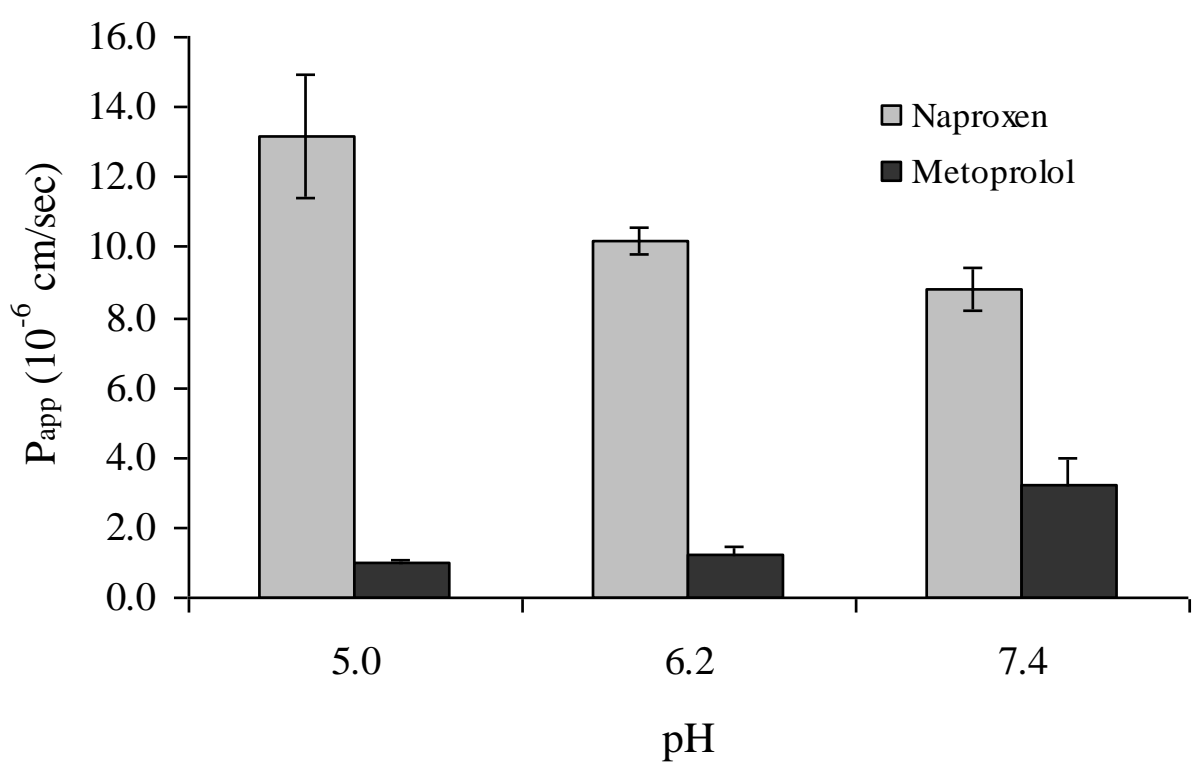

Figure 7

Figure 7: The permeability values for naproxen and metoprolol at $\mathrm{pH} 5.0,6.2$ and 7.4 in the donor chamber and $\mathrm{pH} 7.4$ in the acceptor chamber. 
Table 1: The concentrations of the different co-solvents and tensides used in the permeability experiments with calcein

\begin{tabular}{|c|c|c|c|c|c|c|c|c|}
\hline \multirow{2}{*}{$\begin{array}{c}\text { Solubility enhancing } \\
\text { agent }\end{array}$} & \multirow{2}{*}{$\begin{array}{l}\text { Critical micelle } \\
\text { concentration }(\mathrm{cmc})\end{array}$} & \multicolumn{7}{|c|}{ Concentration (mg/ml) } \\
\hline & & 0.5 & 1 & 5 & 7.5 & 10 & 20 & 40 \\
\hline Span 20 & $0.5 \mu \mathrm{g} / \mathrm{ml}^{\mathrm{a}}$ & & $\mathrm{x}$ & $\mathrm{X}$ & $\mathrm{X}$ & $\mathrm{X}$ & $X$ & $\mathrm{X}$ \\
\hline Tween 80 & $0.01 \mathrm{mg} / \mathrm{ml}^{\mathrm{b}}$ & $\mathrm{x}$ & $\mathrm{X}$ & & & & & \\
\hline Brij 35 & $0.07 \mathrm{mg} / \mathrm{ml}^{\mathrm{b}}$ & $\mathrm{x}$ & $\mathrm{x}$ & $\mathrm{x}$ & & & & \\
\hline Cremophore EL & $0.08 \mathrm{mg} / \mathrm{ml}^{\mathrm{c}}$ & & $\mathrm{x}$ & $x$ & & & $\mathrm{X}$ & \\
\hline Ethanol & - & & $\mathrm{x}$ & $\mathrm{x}$ & & $\mathrm{x}$ & $\mathrm{X}$ & $\mathrm{x}$ \\
\hline DMSO & - & & $\mathrm{x}$ & $\mathrm{x}$ & & $\mathrm{X}$ & $\mathrm{x}$ & $\mathrm{x}$ \\
\hline PEG 400 & - & & & & & & $\mathrm{X}$ & $X$ \\
\hline
\end{tabular}

Hait, S.K. and Moulik, S.P., 2001. Determination of critical micelle concentration (CMC) of nonionic surfactants by donor-acceptor interaction with iodine and correlation of CMC with hydrophile-lipophile balance and other parameters of the surfactants, J Surfact Detergents 4, 303-309

Lin, S.Y.D. and Krochta, J.M., 2005. Whey protein coating efficiency on surfactant-modified hydrophobic surfaces, J Agricult Food Chem 53, 5018-5023

Nerurkar, M.M., Ho, N.F.H., Burton, P.S., Vidmar, T.J. and Borchardt, R.T., 1997. Mechanistic roles of neutral surfactants on concurrent polarized and passive membrane transport of a model peptide in Caco-2 cells, J Pharm Sci 86, 813-821 
Table 2: The permeability $\left(\mathrm{P}_{\mathrm{app}}\right)$ values for calcein in absence (control) and presence of various tensides and co-solvents in the donor chamber. ${ }^{a}$

\begin{tabular}{|c|c|c|c|c|c|c|c|c|}
\hline & Control & $\begin{array}{c}0.5 \\
\mathrm{mg} / \mathrm{ml}\end{array}$ & $\begin{array}{c}1 \\
\mathrm{mg} / \mathrm{ml}\end{array}$ & $\begin{array}{c}5 \\
\mathrm{mg} / \mathrm{ml}\end{array}$ & $\begin{array}{c}7.5 \\
\mathrm{mg} / \mathrm{ml}\end{array}$ & $\begin{array}{c}10 \\
\mathrm{mg} / \mathrm{ml}\end{array}$ & $\begin{array}{c}20 \\
\mathrm{mg} / \mathrm{ml}\end{array}$ & $\begin{array}{c}40 \\
\mathrm{mg} / \mathrm{ml}\end{array}$ \\
\hline Control & $\begin{array}{l}0.061 \\
(0.05)\end{array}$ & & & & & & & \\
\hline Span 20 & & & $\begin{array}{c}0.072 \\
(0.007)\end{array}$ & $\begin{array}{c}0.066 \\
(0.006)\end{array}$ & $\begin{array}{l}0.129 * \\
(0.026)\end{array}$ & $\begin{array}{l}0.295^{*} \\
(0.012)\end{array}$ & $\begin{array}{l}0.575^{*} \\
(0.047)\end{array}$ & $\begin{array}{l}0.727 * \\
(0.105)\end{array}$ \\
\hline Tween 80 & & $\begin{array}{l}0.529 * \\
(0.046)\end{array}$ & $\begin{array}{l}0.836^{*} \\
(0.030)\end{array}$ & & & & & \\
\hline Brij 35 & & $\begin{array}{l}1.156^{*} \\
(0.111)\end{array}$ & $\begin{array}{l}1.468 * \\
(0.076)\end{array}$ & & & & & \\
\hline Cremophor & & & $0.475^{*}$ & 0.938 & & & $1.554 *$ & \\
\hline EL & & & $(0.02)$ & (0.398) & & & $(0.118)$ & \\
\hline PEG 400 & & & & & & & $\begin{array}{c}0.076 \\
(0.023)\end{array}$ & $\begin{array}{r}0.047 \\
(0.008)\end{array}$ \\
\hline Ethanol & & & $\begin{array}{c}0.057 \\
(0.004)\end{array}$ & $\begin{array}{c}0.066 \\
(0.006)\end{array}$ & & $\begin{array}{c}0.056 \\
(0.001)\end{array}$ & $\begin{array}{c}0.081 \\
(0.023)\end{array}$ & $\begin{array}{l}0.102 \\
(0.047)\end{array}$ \\
\hline DMSO & & & $\begin{array}{c}0.049 \\
(0.009)\end{array}$ & $\begin{array}{c}0.049 \\
(0.004)\end{array}$ & & $\begin{array}{c}0.061 \\
(0.016)\end{array}$ & $\begin{array}{c}0.091 \\
(0.024)\end{array}$ & $\begin{array}{r}0.048 \\
(0.011)\end{array}$ \\
\hline
\end{tabular}

${ }^{a}$ The $\mathrm{P}_{\text {app }}$ values are given in $10^{-6} \mathrm{~cm} / \mathrm{sec}$ and the standard deviations are given in parentheses.

* The permeability values that were significantly $(\mathrm{p}=0.05)$ different from control. 